\title{
Surface Modification with Zwitterionic Cysteine Betaine for Nanoshells-Assisted Near-Infrared Plasmonic Hyperthermia
}

Chun-Jen Huang, ",\#,* Sz-Hau Chu, 'Chien-Hung Li, and T. Randall Lee

Department of Biomedical Sciences and Engineering, ${ }^{\#}$ Department of Chemical and Materials Engineering, National Central University, Jhong-Li, Taoyuan 320, Taiwan

Department of Chemistry and the Texas Center for Superconductivity, University of Houston, Houston, Texas 77204-5003, United States

* Email: cjhuang@ncu.edu.tw (C.-J.H.) 


\section{ABSTRACT}

Nanoparticles decorated with biocompatible coatings have received considerable attention in recent years for their potential biomedical applications. However, the desirable properties of nanoparticles for in vivo uses, such as colloidal stability, biodistribution, and pharmacokinetics, require further research. In this work, we report a bio-derived zwitterionic surface ligand, cysteine betaine (Cys-b) for the modification of hollow gold-silver nanoshells, giving rise to hyperthermia applications. Cys-b coatings on planar substrates and nanoshells were compared to conventional (11-mercaptoundecyl)tri(ethylene glycol) (OEG-thiol) to investigate their effects on the fouling resistance, colloidal stability, environmental tolerance, and photothermal properties. The results found that Cys-b and OEG-thiol coatings exhibited comparable antifouling properties against bacteria of gram-negative $P$. aeruginosa and gram-positive $S$. epidermidis, NIH-3T3 fibroblasts, and bovine serum albumin. However, when the modified nanoshells were suspended at a temperature of $50{ }^{\circ} \mathrm{C}$ in aqueous $3 \mathrm{M} \mathrm{NaCl}$ solutions, shifts in the extinction maximum of the OEG-capped nanoshells with time were observed, while the corresponding spectra of nanoshells capped with Cys-b generally remained unchanged. In addition, when the nanoshells were continuously exposed to NIR irradiation, the temperature of the solution containing nanoshells capped with Cys-b increased to a plateau of $54{ }^{\circ} \mathrm{C}$, while that of the OEG-capped nanoshells gradually decreased after reaching a peak temperature. Accordingly, the Cys-b nanoshells were conjugated with anti-HER2 antibodies for targeted delivery to HER2-positive MDA-MB-453 breast cancer cells for hyperthermia treatment. The results showed the selective delivery and effective photothermal cell ablation with the antibody-conjugated Cys-b nanoshells. Therefore, this work demonstrated the promise of bio-derived zwitterionic Cys-b as a stable and biocompatible surface coating for materials in nanomedicine.

Keywords: Zwitterionic materials, antifouling coating, nanomaterials, hyperthermia, bioinspired materials, cancer therapy. 


\section{INTRODUCTION}

Hyperthermia, which involves the introduction of moderate heat to a specific target, has become an important method for tumor therapy because of the limited tolerance of tumor cells to a temperature range of $41-47{ }^{\circ} \mathrm{C}[1,2]$. These elevated temperatures cause irreversible cell damage by loosening cell membranes and denaturing proteins. The heating sources applied include radio frequency, microwaves, and ultrasound waves. However, these sources suffer from drawbacks because of their associated damage to the surrounding healthy tissues. An alternative strategy is photothermal therapy (PTT) in which photothermal agents are employed for heat generation in a local environment [3-6]. The agents can be dye molecules such as naphthalocyanines, indocyanine, and porphyrins coordinated to transition metals. However, these chromophores suffer from low absorption coefficients and poor photostability [7, 8]. In recent years, tremendous advances have been witnessed in the development of nanomaterials with unique optical properties [9-11]. More specifically, novel metal nanoparticles have been employed as powerful agents for PTT because of their robust photostability and strong optical response via the surface plasmon resonance (SPR). A variety of plasmonic nanostructures including nanospheres, $[12,13]$ nanoshells $[14,15]$, nanorods $[16,17]$, and nanocages $[18]$, have been developed that respond to wavelengths in the visible and near infrared (NIR) regions. In the PTT applications, in addition to a strong extinction, the nanoparticle agents should possess additional properties, such as nontoxicity, long-term colloidal stability, high biocompatibility, and facile functionalization [19]. These requirements shed light on the critical role of surface chemistry for decorating plasmonic nanomaterials for their effective and safe implementations.

Commonly, thiolated oligo(ethylene glycol) (OEG) adsorbates are employed as capping ligands, in which thiol groups are adsorbed onto the surface of gold nanostructures via thiol-gold 
bonds[20]. OEG-modified nanoparticles can significantly enhance colloidal stability, biocompatibility, and biodistribution [21]. Because of its steric repulsion with an elastic and osmotic component [22-24], OEG coatings serve as antifouling materials to repel nonspecific adsorptions. Nevertheless, several factors must be considered when using OEG coatings under complex conditions [24]. For example, OEG adsorbates form hydrogen bonds with water molecules, and thus the conformational change and packing density of the oligomeric ethylene glycol can significantly affect the interfacial water layers [25]. In addition, enhanced temperature and ionic strength in the environment induce changes in the OEG conformation from a helical to an all-trans form, which leads to weakening of the bonding to interfacial water molecules [26]. Furthermore, the poor hydration of OEG eventually gives rise to energetically favorable nonspecific adsorptions [27]. Additionally, OEG can undergo degradation under the stresses of heat and light irradiation, and the possible formation of hydroperoxides [21, 28, 29]. Taken together, an alternative coating material to OEG for use in particular cases, such as plasmonic nanoparticles for the photothermal therapy, remains highly desirable.

In recent years, attentions have been paid to zwitterionic materials, which contain both positively and negatively charged groups. These materials interact strongly with water molecules through ionic solvation, leading to stable configurations at high temperature and ionic strength [27, 30-33]. Analogously, in nature, cell membranes are comprised largely of amphiphilic lipids containing polar zwitterionic groups that resist nonspecific adsorptions and allow highly selective biorecognition at interfaces. Therefore, an increasing number of applications utilizing zwitterionic materials as biocompatible and antifouling coatings for complex environments have been explored [30, 31, 34-36]. Our group recently reported the study and development of a novel zwitterionic surface ligand, cysteine betaine (Cys-b), which is derived from the natural 
organosulfur compound, cysteine, by converting its primary amine to a quaternary ammonium [37]. We showed that this branched zwitterionic group has a high tolerance to $\mathrm{pH}$ changes and resistance to photooxidation in the presence of oxygen and light irradiation [37]. Moreover, selfassembled monolayers (SAMs) of Cys-b on gold exhibit better repellence than cysteine against proteins, bacteria, and mammalian cells. Therefore, the unique features of Cys-b make it promising as a new nanoscale coating material for potential implementation in the modification of plasmonic nanomaterials for PTT.

In the research reported here, we conducted a comparative study between Cys-b and thiolated OEG coatings on both planar "flat" gold surfaces and on plasmonic gold-based nanoparticles. The formation of SAMs on the flat gold surfaces was examined by contact angle measurements and X-ray photoelectron spectroscopy (XPS). Fouling tests on modified substrates were carried out with protein, bacteria, and NIH 3T3 cells. Importantly, the colloidal stability of plasmonic hollow gold-silver nanoshells coated with Cys-b and OEG-thiol was investigated by UV-vis spectroscopy and dynamic light scattering (DLS) to follow the changes in light absorbance/scattering and hydrodynamic sizes, respectively. The photothermal properties of modified nanoparticles as PTT agents were confirmed by NIR irradiation and the measurement of temperature changes in solutions. Finally, we demonstrated the effectiveness of Cys-b modified hollow gold-silver nanoshells conjugated with anti-HER2 antibodies against MDA-MB-453 breast cancer cells in hyperthermia treatments. These studies provided not only insight into the potential benefits of Cys-b as a zwitterionic surface ligands for plasmonic nanoparticles, but also evidence of a robust surface strategy for maintaining bioinertness in complex environments. 


\section{EXPERIMENTAL SECTION}

\subsection{Materials}

L-Cysteine, potassium hydroxide $(\mathrm{KOH})$, dimethyl sulfate, trifluoroacetic acid (TFA), glacial acetic acid, acetone, silver nitrate, potassium carbonate, N-hydroxysuccinimide (NHS), and (1ethyl-3-(3-dimethylaminopropyl)carbodiimide) (EDC) were purchased from Sigma-Aldrich. (11-Mercaptoundecyl)tri(ethylene glycol) (OEG-thiol) and thiol-PEG6-acid (COOH-thiol) were purchased from Broadpharm. Anti-HER2 mouse antibodies and anti-mouse $\operatorname{IgG}(\mathrm{H}+\mathrm{L})$ conjugated with Alexa Fluor 488 were obtained from Cell Signaling Technology. Trisodium citrate dihydrate and nitric acid were obtained from EM Science. Hydrogen tetrachloroaurate(III) hydrate $\left(\mathrm{HAuCl}_{4}{ }_{4} \mathrm{H}_{2} \mathrm{O}\right)$ was purchased from Strem. Bovine serum albumin (BSA) was obtained from MDBio Inc. Dulbecco's Modified Eagle's Medium (DMEM) and fetal bovine serum (FBS) were obtained from Gibco. Luria-Bertani broth (LB broth) was obtained from BD. Water was purified to a resistivity of $18 \mathrm{M} \Omega^{\circ} \mathrm{cm}$ using the Academic Milli-Q Water System (Millipore Corporation) and filtered using a $0.22 \mu \mathrm{m}$ filter.

\subsection{Cys-b Synthesis}

The detailed experimental procedure for Cys-b synthesis has been described [37]. Briefly, a flask containing $1 \mathrm{~g}$ of cysteine in $3 \mathrm{~mL}$ of deionized water was immersed in an ice bath and stirred under nitrogen. An $8.5 \mathrm{~mL}$ aliquot of $6.5 \mathrm{M} \mathrm{KOH}$ was introduced dropwise until the cysteine dissolved. The residual $\mathrm{KOH}$ and $5.2 \mathrm{~mL}$ of dimethyl sulfate were dropped in simultaneously over $1 \mathrm{~h}$ with stirring. Afterward, the flask was kept for another $20 \mathrm{~min}$ at $\mathrm{rt}$, and then $1.2 \mathrm{~mL}$ of glacial acetic acid was added. The solution was evaporated in vacuo to a volume 
of around $2 \mathrm{~mL}$. The byproduct potassium methyl sulfate was precipitated by adding $40 \mathrm{~mL}$ of ethanol and then filtered. The filtrate was concentrated using a rotovap to a volume of around 2 $\mathrm{mL}$, and then precipitated by adding $50 \mathrm{~mL}$ of acetone. The white product was washed with acetone 5 times to afford pure cysteine betaine, which was reduced in $0.1 \mathrm{M}$ dithiothreitol (DTT) in deionized water and stirred at $65^{\circ} \mathrm{C}$ for $2 \mathrm{~h}$. After cooling, $50 \mathrm{~mL}$ of acetone was added to precipitate the white product of pure Cys-b (70\% yield).

\subsection{Formation of SAMs on Planar Substrates}

$\mathrm{Au}$ thin films with a thickness of $50 \mathrm{~nm}$ on glass slides were prepared by thermal evaporation (I Shien SPS-302). The substrates were cleaned in a sonication bath of $0.1 \%$ SDS, acetone, and ethanol for $10 \mathrm{~min}$ of each, followed by drying under a stream of nitrogen. The substrates were transferred to a plasma cleaner (PDC-001, Harrick Plasma, NY) to expose $\mathrm{O}_{2}$

plasma twice with a power of $10.5 \mathrm{~W}$ for $10 \mathrm{~min}$. The clean substrates were immediately immersed into a $1 \mathrm{mM}$ Cys-b solution in DI water containing 2\% TFA or $1 \mathrm{mM}$ OEG-thiol solution in ethanol, and shaken at $50 \mathrm{rpm}$ at room temperature for $12 \mathrm{~h}$. The modified substrates were removed and cleaned with deionized water, ethanol, and water, followed by drying under a stream of nitrogen [38].

\subsection{Contact Angle Measurements}

Static water contact angles were accessed by using an optical contact angle goniometer (Phoenix mini, Surface Electro Optics, Seoul). The $5 \mu \mathrm{L}$ water droplets from a microsyringe were placed on the flat gold substrates, and the contact angles were measured at least three times at random positions. 


\subsection{XPS Measurements.}

The elemental spectra were detected by XPS with a microfocused and monochromatic Al K $\alpha$ X-ray source (1486.6 eV, $400 \mu \mathrm{m}$; Sigma Probe, Thermo Scientific). The takeoff angle (with respect to the surface) of the photoelectron was set at $45^{\circ}$. The pressure of the system was below $10^{-10} \mathrm{~Pa}$ using an oil-less ultrahigh vacuum pumping system. A dual beam charge neutralizer (7 $\mathrm{V} \mathrm{Ar}^{+}$and flooding $3 \mathrm{kV}, 1 \mu \mathrm{A}$ electron beam) was employed to compensate for charging effects. Spectra were collected with a pass energy set to $58.7 \mathrm{eV}$, while the binding energy measured was calibrated against the $\mathrm{Au} 4 \mathrm{f}$ peaks at 84 and $88 \mathrm{eV}$. The typical data acquisition time was around $30 \mathrm{~min}$.

\subsection{Bacterial Fouling Tests}

After inoculation for $16 \mathrm{~h}$ in LB in a conical flask at $37^{\circ} \mathrm{C}$ shaking at $200 \mathrm{rpm}$, the bacteria of $S$. epidermidis or $P$. aeruginosa were then washed with sterile PBS for three times through centrifugation at $4000 \mathrm{rpm}$ for $5 \mathrm{~min}$ and re-suspension in PBS. After the final wash, the bacterial samples in PBS were diluted to an optical density reading at $670 \mathrm{~nm}$ (OD670) of 0.1, corresponding to $\sim 8 \times 10^{7}$ cells $/ \mathrm{mL}$, for testing the antifouling properties of substrates modified with OEG-thiol and Cys-b. The substrates were dipped into the bacterial solution at $37{ }^{\circ} \mathrm{C}$ for 3 $\mathrm{h}$, followed by washing with PBS and shaking at $100 \mathrm{rpm}$ for $5 \mathrm{~min}$ for three times. The adsorbed bacteria were stained with $50 \mu \mathrm{L}$ of LIVE/DEAD BacLight for $15 \mathrm{~min}$. Afterward, the substrates were observed using fluorescence microscopy (ZEISS Microscope Axio Obserber A1, Germany) with a magnification of $400 \times$ and an excitation wavelength of $488 \mathrm{~nm}$. The measurements were performed at five random locations on each sample, and the bacteria 
numbers were analyzed using an ImageJ software package (developed at National Institutes of Health, MA).

\subsection{Cell Adhesion Tests}

$3 \mathrm{~T} 3$ fibroblasts were maintained in DMEM with $10 \% \mathrm{FBS}$ at $37^{\circ} \mathrm{C}$ in an incubator with $95 \%$ relative humidity and $5 \% \mathrm{CO}_{2}$. The bare $\mathrm{Au}$ substrates and $\mathrm{Au}$ substrates modified with Cys-b and OEG-thiol were sterilized in $75 \%$ ethanol for $30 \mathrm{~s}$ and then washed with PBS for 3 min before cell seeding. The substrates were placed in a 24-well plate, and 3T3 fibroblasts in DMEM with $1 \%$ FBS were introduced with a total cell number of $2 \times 10^{5}$ per well. After culture for $72 \mathrm{~h}$, the substrates were washed with PBS, followed by imaging using an optical microscopy. The cell number and cell coverage area were estimated using ImageJ software.

\subsection{Preparation of Gold-Silver Nanoshells}

Silver nanoparticles were prepared using the method of Lee and Meisel [39]. Briefly, an aliquot of $\mathrm{AgNO}_{3}(0.0340 \mathrm{~g}, 0.200 \mathrm{mmol})$ was dissolved in $200 \mathrm{~mL}$ of $\mathrm{H}_{2} \mathrm{O}$. The solution was brought to reflux, and then $4 \mathrm{~mL}$ of $1 \%$ trisodium citrate solution was added under vigorous stirring. The solution continued to reflux for $25 \mathrm{~min}$. The contents turned a yellow green color, indicating the presence of silver nanoparticles. The solution was allowed to cool to rt and then centrifuged at $6000 \mathrm{rpm}$ for $15 \mathrm{~min}$. The nanoparticles were then re-dispersed in $25 \mathrm{~mL}$ of water. This procedure generated monodispersed silver nanoparticles, where the size could be adjusted from $40 \mathrm{~nm}$ to $100 \mathrm{~nm}$, depending on the concentration of the reactants. For the synthesis of hollow gold-silver nanoshells as described in previous studies $[15,40,41], 0.050 \mathrm{~g}$ of $\mathrm{K}_{2} \mathrm{CO}_{3}$ was added to $200 \mathrm{~mL}$ of purified water, which was then injected into $4 \mathrm{~mL}$ of $1 \%$ 
$\mathrm{HAuCl}_{4}{ }_{4} \mathrm{H}_{2} \mathrm{O}$ solution. The mixture, initially yellow in color, became colorless 30 min after the reaction was initiated. The flask was then covered with aluminum foil to shield it from light, and the solution was stored in a refrigerator overnight. To obtain surface plasmon resonance (SPR) maxima centered at $\sim 800 \mathrm{~nm}$ using the gold-silver nanoshell solutions, $20 \mathrm{~mL}$ of silver nanoparticles solution were mixed with $200 \mathrm{~mL} \mathrm{~K}$-gold solution and stirred for $4 \mathrm{~h}$. The SPR band of the solution was tracked using UV-vis measurements. The nanoshells were isolated by centrifugation at $6000 \mathrm{rpm}$ for $15 \mathrm{~min}$, and the supernatant was then decanted. The particles were re-dispersed in $22.5 \mathrm{~mL}$ water. The size and morphology of the nanoparticles were evaluated using a LEO-1525 scanning electron microscope (SEM, Carl Zeiss, Germany, Figure S1 in Supplementary Data) operating at an accelerating voltage of $15 \mathrm{kV}$ and dynamic light scattering (DLS, Nano-S, Malvern, UK) (Figure 1S). The mean diameter of the nanoshells was $102 \pm 21 \mathrm{~nm}$. The concentration of nanoshells obtained from nanoparticle tracking analysis technology (NanoSight NS300, Malvern, UK) and the measured nanoshells concentration was $\sim 10^{11}$ nanoparticles/mL. Extinction spectra were collected over the wavelength range of 200$1000 \mathrm{~nm}$ with all nanoshell samples suspended in PBS for the measurements.

\subsection{Colloidal Stability Tests}

For the nanoshell modification, the total amount of the ligands, Cys-b and OEG-thiol, was $10^{7}$ equivalent to nanoshells in deionized water by ligand exchange. The modification process was conducted for $12 \mathrm{~h}$ at rt, followed by collecting and washing with PBS via centrifugation at 9,000 rpm for $10 \mathrm{~min}$. The particles were re-suspended in PBS. The changes in maximum extinction peak and particle sizes were monitored using UV-vis spectroscopy and DLS. With regard to the effects of protein fouling, the nanoshell solutions were diluted 5 times at a 
concentration of $\sim 2 \times 10^{10}$ nanoshells $/ \mathrm{mL}$ were prepared. BSA protein was added to the nanoshell solutions to a concentration of $4.9 \mathrm{mg} / \mathrm{mL}$ and the changes in the hydrodynamic size of nanoshells as a function of time were followed by dynamic light scattering (DLS, SZ-100 Horiba) measurements. To verify the colloidal stability of modified nanoshells in the presence of high ionic strength and heat, the nanoshells modified with Cys-b and OEG-thiol were dissolved in $3 \mathrm{M} \mathrm{NaCl}$ solution, and the temperature was maintained at $50{ }^{\circ} \mathrm{C}$. The extinction spectra were recorded for $24 \mathrm{~h}$ using the UV-vis spectroscopy.

\subsection{Antibody Conjugation}

For targeted hyperthermia applications with the nanoshells, anti-HER2 mouse monoclonal antibody was used to conjugate onto the nanoshells for delivery to HER2-positive MDA-MB453 cell line. MDA-MB-453 cells were maintained in DMEM supplemented with 10\% FBS at $37^{\circ} \mathrm{C}$ in a humidified $\mathrm{CO}_{2}$ incubator. In the beginning, the nanoshells were modified with carboxyl group termination by mixing $\mathrm{COOH}$-thiol with Cys-b or OEG-thiol at a mole ratio of 1:4, respectively. The as-prepared nanoshells in $\mathrm{DI} \mathrm{H}_{2} \mathrm{O}$ at a concentration of $\sim 2 \times 10^{10}$ nanoshells $/ \mathrm{mL}$ were treated with the mixed thiol solutions at a total concentration of $5 \mu \mathrm{M}$ at $\mathrm{rt}$ for $48 \mathrm{~h}$. After ligand exchange, the $\mathrm{COOH}$-functionalized nanoshells were collected by centrifugation at 20,000 rpm for $10 \mathrm{~min}$ and redispersed in PBS. The carboxyl groups were activated by EDC/NHS amine coupling chemistry. The activation solution was prepared from dissolving $18 \mathrm{mg}$ of EDC and $1.2 \mathrm{mg}$ of NHS in $1 \mathrm{~mL}$ of PBS. A $1 \mathrm{~mL}$ aliquot of the activation solution was transferred to the modified-nanoshells solution at a concentration of $\sim 2 \times 10^{10}$ nanoshells $/ \mathrm{mL}$ in PBS at $4{ }^{\circ} \mathrm{C}$ for $2 \mathrm{~h}$. Afterward, the activated nanoshells were collected by centrifugation at 20,000 rpm for 10 min and washing for three times with fresh PBS to remove 
unreacted chemicals. The activated nanoshells at a concentration of $\sim 2 \times 10^{10}$ nanoshells $/ \mathrm{mL}$ were incubated with anti-HER2 $\mathrm{Ab}$ at a concentration of $1 \mu \mathrm{g} / \mathrm{mL}$ in PBS at $\mathrm{rt}$ for $3 \mathrm{~h}$ for protein conjugation. The anti-HER2 Ab-conjugated nanoshells were collected by centrifugation at 20,000 rpm for $10 \mathrm{~min}$ and washing for three times with fresh PBS to remove free antibodies. The conjugated nanoshells were stored in a refrigerator at $4{ }^{\circ} \mathrm{C}$ and used for cell studies within one week. The presence of the anti-HER2 Ab on nanoshells was confirmed by adding antimouse $\operatorname{IgG}(\mathrm{H}+\mathrm{L})$ conjugated with Alexa Fluor 488 and probing the fluorescence signal with a multi-detection microplate reader (Synergy HT, Biotek, VT). In addition, Fourier transform infrared spectroscopy (FTIR) was applied to identify the presence of proteins after conjugation (Figure S2). It was estimated by the previous reports that the binding capacities of proteins on nanoparticles are in a range of $44-90 \mu \mathrm{g}$ per mg NPs [42-44].

\subsection{Hyperthermia Tests}

HER2-positive MDA-MB-453 breast tumor cells and HER2-negative NIH 3 T3 fibroblasts were seeded onto a 96-well plate at a density of 10,000 cells per well for 2 days before the tests. The cells were washed three times with PBS, followed by incubation with nanoshells both with and without anti-HER2 $\mathrm{Ab}$ at $37{ }^{\circ} \mathrm{C}$ for $2 \mathrm{~h}$. After incubation, the cells were irradiated with a NIR laser having a wavelength centered at $808 \mathrm{~nm}$ at an output power of $2.3 \mathrm{~W} / \mathrm{cm}^{2}$ for $10 \mathrm{~min}$. The cells were then washed with PBS and stained with calcein AM for visualization of live cells and with EthD-1 for visualization of dead cells. Software ImageJ was applied to quantify the cell death percentage after exposure to NIR irradiation. 


\section{RESULTS and DISUSSION}

\subsection{SAM Formation on Planar Substrates}

To compare the interfacial properties of Cys-b and OEG-thiol SAMs, the adsorbates were dissolved in solvents and allowed to form SAMs on flat Au substrates. Because of the interplane electrostatic forces, the oppositely charged ions between amphoteric amino acids can interact to form a multilayer structure, leading to an unbalanced interfacial charge and incomplete formation of monolayers [45]. Therefore, we prepared Cys-b SAMs using treatments of TFA to disrupt the interplane electrostatic forces between free and bound molecules on the surface [37, 46]. Elemental compositions and interfacial wettability of the SAMs were determined by XPS analysis and contact angle measurements, respectively. Figure 1 shows the XPS spectra of the $\mathrm{C} 1 \mathrm{~s}, \mathrm{~N} 1 \mathrm{~s}$, and $\mathrm{S} 2 \mathrm{p}$ regions for the Cys-b and OEG-thiol SAMs. The de-convoluted C 1s peak for the Cys-b SAM centered at $289.1 \mathrm{eV}$ can be assigned to $-\mathrm{O}-\underline{\mathrm{C}}=\mathrm{O}$, indicating the presence of the carboxylate group in Cys-b $[47,48]$. The two distinct peaks at 286.5 and $285.0 \mathrm{eV}$ in the $\mathrm{C} 1 \mathrm{~s}$ spectrum of the OEG-thiol SAM can be assigned as -O- $\underline{\mathrm{C}}$ - and $-\mathrm{C}-\underline{\mathrm{C}}$ - in the OEG structure, respectively [49-51]. For the $\mathrm{N} 1 \mathrm{~s}$ spectra, the Cys-b SAM shows a peak at $403.1 \mathrm{eV}$, which arises from the quaternary ammonium in Cys-b. The observation of no peaks in the $\mathrm{N} 1 \mathrm{~s}$ spectra of the OEG-thiol SAM is consistent with its chemical structure. The presence of bound sulfur for both types of SAMs was confirmed by the appearance of the S 2p peaks at 162.0 and 163.2 $\mathrm{eV}$ [46]. The ratio of $\mathrm{S} / \mathrm{N}$ for Cys-b is close to 1 , which was in agreement with the stoichiometry [37]. Herein, the peaks for oxidized sulfur and unbound thiols centered at 166.0 and $164.0 \mathrm{eV}$, respectively, were not observed in the two SAMs, indicating the efficient formation of SAMs on gold [46]. 
Figure 2 shows the static contact angles for samples of bare gold and gold modified with Cys-b and OEG-thiol. The contact angles changed from $59 \pm 4^{\circ}$ for the unmodified substrate to $7 \pm 1^{\circ}$ and $21 \pm 3^{\circ}$ for the substrates modified with Cys-b and OEG-thiol, respectively, which is in agreement with previous studies [37, 51]. Herein, due to strong ionic solvation, the Cys-b SAMs exhibited greater hydrophilicity than the OEG-thiol SAMs, consistent with a model in which the Cys-b-modified surfaces possess superhydrophilic characteristics with a tightly bound water layer. Notably, OEG, which interacts through hydrogen bonding with contacting water molecules, exhibits an amphiphilic nature that facilitates the dissolution of both aqueous and organic phases $[52,53]$.

To test the capability of the coatings in fouling resistance, we exposed bare $\mathrm{Au}$ and $\mathrm{Au}$ modified with Cys-b and OEG-thiol to gram-negative P.aeruginosa and gram-positive S. epidermidis for $3 \mathrm{~h}$ at $37^{\circ} \mathrm{C}$. After gently washing with PBS to remove suspended and loosely bound bacteria, adhered bacteria were stained with Live/Dead dye for cell viability assays and imaged using fluorescence microscopy (Figure 3a). Notably, the numbers of bacteria on the Cys-b and OEG-thiol SAMs were reduced with respect to the bare Au substrates for the two strains of bacteria. In addition, P. aeruginosa is more adhesive than S. epidermidis, manifested by a large amount of adhered $P$. aeruginosa on bare $\mathrm{Au}$. The difference can be attributed to the higher expression level of the capsular exopolysaccharide of $P$. aeruginosa, which facilitates the adhesion of bacteria [54]. The quantitative results shown in Figure $3 \mathrm{~b}$ reveals that the numbers of the adsorbed P. aeruginosa and S. epidermidis were suppressed by about 3 and 2 orders of magnitude, respectively, compared with that on bare Au. In this work, the difference between Cys-b and OEG-thiol SAMs in antibacterial adhesion was insignificant. 
The cell number and cell spreading area were determined to evaluate the cellular adaptation to the surface chemistries. In this study, NIH $3 \mathrm{~T} 3$ fibroblasts were seeded on substrates of bare $\mathrm{Au}$ and Au modified with Cys-b and OEG-thiol, followed by culturing for $72 \mathrm{~h}$. The cells were then washed with PBS to remove loosely bound cells and imaged using the bright-field microscopy (Figure 4a), which showed that the numbers and cell spreading areas of fibroblasts on the substrates modified with Cys-b and OEG-thiol were lower than those on the bare Au substrate. In addition, the cells on the bare Au substrate exhibited bipolar shapes, whereas those on the Cys-b and OEG SAMs were round in appearance. The results indicated a reduction in cell adhesion and spreading dynamic equilibrium for the modified surfaces [55], reflecting the antifouling efficiency of the Cys-b and OEG coatings. The quantitative results are shown in Figure $4 \mathrm{~b}$. The cell numbers were reduced by 85 and $86 \%$ on the SAMs derived from Cys-b and OEG-thiol, respectively, relative to the bare Au substrate. Moreover, the relative cell spreading areas on the SAMs derived from Cys-b and OEG-thiol were estimated to be $14 \pm 2$ and $12 \pm 3 \%$, respectively, relative to the bare $\mathrm{Au}$ substrate. In terms of the cell adhesion and growth, the two modified surfaces show no significant differences when compared to each other.

\subsection{Modification of Hollow Gold-Silver Nanoshells}

Hollow gold-silver nanoshells were coated with Cys-b and OEG-thiol, and the resultant materials were evaluated on the basis of optical properties, fouling resistance, colloidal stability, and function in hyperthermia applications. The extinction spectra of as-prepared nanoshells and nanoshells modified with Cys-b and OEG-thiol are shown in Figure 5a. The extinction maximum of the modified nanoshells slightly red-shifted from $817 \mathrm{~nm}$ to 832 and $843 \mathrm{~nm}$ for the Cys-band OEG-modified nanoshells, respectively. The fouling resistance of the nanoshells was evaluated by DLS by measuring the increase in particle size as a function of the incubation time 
in the presence of the BSA solution. As shown in Figure 5b, the fouling level of the as-prepared nanoshells is more prominent than that for modified nanoshells. After exposure to BSA for $5 \mathrm{~h}$, the increment of the particle size for the as-prepared nanoshells is $315 \pm 26 \mathrm{~nm}$, whereas, those for the nanoshells modified with Cys-b and OEG-thiol were about $97 \pm 26$ and $99 \pm 28 \mathrm{~nm}$, which is roughly a $70 \%$ reduction compared with the unmodified sample. The increase in the particle sizes likely arises from the formation of protein corona and colloidal aggregation in the BSA solution. Note the concentration of BSA solution was adjusted to $4.9 \mathrm{mg} / \mathrm{mL}$, which is about $10 \%$ that in human blood. The as-prepared nanoshells were capped with citrate, which gives rise to a negatively charged surface that is colloidally stable in aqueous solution. Although the colloidal stability with citrate has been confirmed, the non-specific adsorption arising from electrostatic interactions cannot be excluded. In contrast, highly dispersed Cys-b- and OEGmodified nanoshells impart resistance to the adsorption of BSA, which can be attributed to the charge balance and hydrophilicity of the surface. Again, the differences between coatings derived from Cys-b and OEG-thiol appear to be insubstantial.

The plasmonic hollow gold-silver nanoshells were synthesized using established methods,[40] by which the light extinction can be tuned from the visible to the NIR regions according to the size of particles and the composition of the alloy. The nanoshells with extinction in the NIR region at wavelengths of $800-1200 \mathrm{~nm}$ are particularly attractive for biomedical applications because the range of wavelengths is referred to as the "tissue transparency window" [56]. Thus, potential applications of nanoshells in nanomedicine, including photothermal cancer therapy [57-59] and photothermally triggered drug release, have been investigated $[60,61]$. However, for the full exploitation of nanodevices, the capping chemistry must be able to endure high temperature, strong light irradiation, and complex biological environments. 
OEG-based SAMs have been employed as a model surface for studying biorecognition processes by taking advantage of well-defined compositions and control over molecular adsorption. Thus, OEG SAMs play important roles in a variety of biosensing applications when coupled with analytical techniques such as SPR spectroscopy,[62, 63] optical ellipsometry [64], and quartz crystal microbalance [65]. In addition, the capability to spatially decorate the surfaces into a microscale array facilitates high-throughput screening for new drugs, biomarkers, and diagnostic techniques $[66,67]$. Importantly, when compared to OEG-thiol, our new superhydrophilic zwitterionic ligand, Cys-b, shows comparable antifouling properties against the adsorption of proteins, bacteria, NIH 3 T3 fibroblasts. In addition, the molecular weight of Cys-b (163 Da) is smaller than OEG-thiol (336 Da), leading to smaller hydrodynamic sizes of nanoparticles coated with Cys-b-coated. In addition, Cys-b resists the photoinduced oxidation to the amino group of Cys and also provides better tolerance toward $\mathrm{pH}$ changes to maintain its zwitterionic character [37]. The colloidal stability and optical properties of the Cys-b-modified nanoparticles show no significant differences with OEG-modified samples under our experimental conditions. Consequently, Cys-b can serve as an alternative to OEG-thiol analogs, and its unique features of superhydrophilicity, photostability, ultra-small size, and environmental insusceptibility make it a particularly attractive nanoscale coating material.

To verify the colloidal stability of modified nanoshells in the presence of the high ionic strength and heat, the nanoshells modified with Cys-b and OEG-thiol were dissolved in $3 \mathrm{M}$ $\mathrm{NaCl}$ solution, and the temperature was maintained at $50{ }^{\circ} \mathrm{C}$, which is comparable to the temperature of solutions containing nanoshells exposed to NIR irradiation at a power density of $4.6 \mathrm{~W} / \mathrm{cm}^{2}$ for $10 \mathrm{~min}$. The extinction spectra were then recorded over $24 \mathrm{~h}$ at $50^{\circ} \mathrm{C}$. Figures $6 \mathrm{a}$, b show that the SPR peaks of the nanoshells modified with Cys-b were optically constant with 
time; in contrast, the nanoshells coated with OEG-thiol underwent a red shift with time. Furthermore, Figure 6c shows a systematically decreasing ratio of the extinction intensities at $808 \mathrm{~nm}$ as a function of irradiation time for the two samples. After $12 \mathrm{~h}$ of heating in $3 \mathrm{M} \mathrm{NaCl}$ solution, the extinction intensity of the OEG-modified nanoshells decreased by $16 \%$. In a related study, NIR light at $808 \mathrm{~nm}$ was used for photolytic heating of the nanoshells in solution over the course of $2 \mathrm{~h}$ (see Figure 6d). This experiment showed that the temperature of the solution can be increased to $\sim 54{ }^{\circ} \mathrm{C}$ within 15 min for nanoshell samples modified with both Cys-b and OEGthiol. After reaching the peak temperature, the temperature plateaued for the Cys-b sample, which likely reflects temperature equilibrium between heat generation from nanoshells and heat loss to the environment. In contrast, the temperature of the OEG-thiol sample gradually decreased with the irradiation time, which likely arises from a loss of photothermal performance due to particle aggregation and precipitation. The latter hypothesis can perhaps be supported by the fact that OEG exhibits a lower critical solution temperature (LCST), leading to dehydration and consequent failure to prevent aggregation at high temperature in salt solutions [27].

\subsection{Hyperthermia Treatments for Cancer Cells}

HER2, which is highly expressed in a significant proportion of breast cancer, ovarian cancer, and gastric cancer, is a ligand for delivery of therapeutic carriers [68-70]. Therefore, the HER2 mAb-conjugated hollow $\mathrm{Au}-\mathrm{Ag}$ nanoshells were synthesized to target the HER2-positive MDAMB-453 breast cancer cells for hyperthermia treatment under NIR irradiation. Surface functionalization was conducted by mixing bio-inert capping ligand (i.e., Cys-b or OEG-thiol) with a functionalizable carboxylate-terminated ligand (i.e., COOH-thiol). The carboxylic acid can be activated by the EDC/NHS amine coupling chemistry $[71,72]$. It was postulated that the 
carboxylate group in Cys-b could also serve as a functional group for protein conjugation as CBassociated polymers $[52,73,74]$. However, because of the limited accessibility and low pKa of the carboxylate group in Cys-b, the efficiency of bioconjugation is largely impracticable. Therefore, we utilized the $\mathrm{COOH}$-thiol as a functional ligand for effective conjugation with antibodies. Nanoshells modified with Cys-b and OEG-thiol both with and without mAb conjugation were incubated with MDA-MB-453 and NIH $3 \mathrm{~T} 3$ at $37{ }^{\circ} \mathrm{C}$ for $2 \mathrm{~h}$, followed by washing with PBS and NIR irradiation for $10 \mathrm{~min}$. The as-synthesized nanoshells without further modification were used as a control sample. Figure 7 provides the photographs and numerical data for live and dead cells analyzed using fluorescence microscopy. Figures $7 \mathrm{a}$ and $\mathrm{b}$ show that the NIH 3 T3 fibroblasts were largely unaffected by NIR irradiation, which is likely due to the limited uptake of nanoshells with modification of the Cys-b and OEG-thiol coatings. Notably, the uptake can be plausibly inhibited by the antifouling properties of the Cys-b and OEG-thiol coatings. In contrast, MDA-MB-453 cells were treated with anti-HER2 mAb-conjugated nanoshells. Figure $7 \mathrm{~b}$ shows that the MDA-MB-453 cells were damaged after exposure to NIR, while the fibroblasts remained largely intact. The quantitative cell death percentages are shown in Figure 7c. After NIR radiation, $92 \pm 9$ and $62 \pm 14 \%$ of the MDA-MB-453 cells were killed upon treatment with Ab-conjugated nanoshells modified with Cys-b and OEG-thiol, respectively. In contrast, less than one percent of the NIH $3 \mathrm{~T} 3$ cells were killed under the same conditions. Thus, the results confirmed the selective delivery of anti-HER2 mAb-conjugated nanoshells into cancer cells through ligand-receptor mediated endocytosis. In addition, nanoshells modified with Cys-b exhibited better thermal ablation of the MDA-MB-453 cells than nanoshells modified with OEG-thiol, likely due to the enhanced photothermal stability and effective delivery of the Cys-b nanoshells. Moreover, small portions $(\sim 10 \%)$ of MDA-MB-453 cells were dead after 
treatment with nanoshells modified with Cys-b and OEG-thiol having no Ab conjugation after sequential NIR irradiation, which we attribute to poor uptake of the nanoshells and/or weak tolerance of the cells to the NIR-induced heat. Consequently, these studies demonstrate the promising use of the Ab-conjugated hollow gold-silver nanoshells modified with Cys-b as an effective and specific tumor ablation agent. 


\section{CONCLUSIONS}

This manuscript describes the evaluation of a new bio-derived antifouling adsorbate, Cys-b, for the modification of plasmonic hollow Au-Ag nanoshells for the hyperthermia treatment of HER2-positive MDA-MB-453 breast cancer cells. Superhydrophilic coatings of Cys-b on Au substrates displayed comparable antifouling properties with conventional OEG-based SAMs, manifested as considerable reduction in bacterial adsorption and adhesion of NIH $3 \mathrm{~T} 3$ fibroblasts. In addition, nanoshells modified with Cys-b exhibited better colloidal stability and photothermal properties at high ionic strength and temperature than those modified with OEG-thiol, indicating that the unique hydration properties of zwitterionic Cys-b are insusceptible to environmental stimuli. In addition, anti-HER2 antibodies were chemically functionalized onto nanoshells modified with Cys-b for the development of an effective and specific tumor ablation agent for the hyperthermia treatment of MDA-MB-453 breast cancer cells. The results indicated that over $90 \%$ of the cells were killed after NIR irradiation for $10 \mathrm{~min}$. Consequently, zwitterionic Cys-b as a nanoscale coating material offers great potential in a wide range of bio-applications.

\section{ACKNOWLEDGMENT}

The authors acknowledge the Ministry of Science and Technology (MOST 104-2221-E-008-108) for financial support of this project. Research efforts at the University of Houston were generously supported by the National Science Foundation (CHE-1411265), the Robert A. Welch Foundation (E-1320), and the Texas Center for Superconductivity at the University of Houston. We thank Ishwar Kumar Mishra for assistance with the nanoshell concentration measurements (NanoSight NS300). 


\section{REFERENCES}

[1] X.H. Huang, P.K. Jain, I.H. El-Sayed and M.A. El-Sayed, Plasmonic photothermal therapy (PPTT) using gold nanoparticles, Lasers Med. Sci., 23 (2008) 217-228.

[2] T. Refaat, S. Sachdev, V. Sathiaseelan, I. Helenowski, S. Abdelmoneim, M.C. Pierce, G. Woloschak, W. Small, B. Mittal and K.D. Kiel, Hyperthermia and radiation therapy for locally advanced or recurrent breast cancer, Breast, 24 (2015) 418-425.

[3] X.M. Liu, H. Chen, X.D. Chen, Y. Alfadhl, J.S. Yu and D.S. Wen, Radiofrequency heating of nanomaterials for cancer treatment: Progress, controversies, and future development, Appl. Phys. Rev., 2 (2015).

[4] D.L. Shi, M.E. Sadat, A.W. Dunn and D.B. Mast, Photo-fluorescent and magnetic properties of iron oxide nanoparticles for biomedical applications, Nanoscale, 7 (2015) 8209-8232.

[5] J. Majeed, L. Pradhan, R.S. Ningthoujam, R.K. Vatsa, D. Bahadur and A.K. Tyagi, Enhanced specific absorption rate in silanol functionalized Fe3O4 core-shell nanoparticles: Study of Fe leaching in Fe3O4 and hyperthermia in L929 and HeLa cells, Colloid Surf. BBiointerfaces, 122 (2014) 396-403.

[6] T.T. Sun, J. Qi, M. Zheng, Z.G. Xie, Z.Y. Wang and X.B. Jing, Thiadiazole molecules and poly(ethylene glycol)-block-polylactide self-assembled nanoparticles as effective photothermal agents, Colloid Surf. B-Biointerfaces, 136 (2015) 201-206.

[7] M.A. Yaseen, J. Yu, M.S. Wong and B. Anvari, Stability assessment of indocyanine green within dextran-coated mesocapsules by absorbance spectroscopy, J. Biomed. Opt., 12 (2007) 64031 .

[8] P.R. Jheng, K.Y. Lu, S.H. Yu and F.L. Mi, Free DOX and chitosan-N-arginine conjugate stabilized indocyanine green nanoparticles for combined chemophotothermal therapy, Colloid Surf. B-Biointerfaces, 136 (2015) 402-412.

[9] E. Boisselier and D. Astruc, Gold nanoparticles in nanomedicine: preparations, imaging, diagnostics, therapies and toxicity, Chem. Soc. Rev., 38 (2009) 1759-1782.

[10] J.H. Gao, H.W. Gu and B. Xu, Multifunctional magnetic aanoparticles: design, synthesis, and biomedical applications, Accounts Chem. Res., 42 (2009) 1097-1107.

[11] D. Ling, N. Lee and T. Hyeon, Chemical synthesis and assembly of uniformly sized iron oxide nanoparticles for medical applications, Accounts Chem. Res., 48 (2015) 1276-1285.

[12] I.H. El-Sayed, X.H. Huang and M.A. El-Sayed, Selective laser photo-thermal therapy of epithelial carcinoma using anti-EGFR antibody conjugated gold nanoparticles, Cancer Lett., 239 (2006) 129-135.

[13] K. Fang, L.N. Song, Z.X. Gu, F. Yang, Y. Zhang and N. Gu, Magnetic field activated drug release system based on magnetic PLGA microspheres for chemo-thermal therapy, Colloid Surf. B-Biointerfaces, 136 (2015) 712-720.

[14] E.R. Riva, A. Desii, E. Sinibaldi, G. Ciofani, V. Piazza, B. Mazzolai and V. Mattoli, Gold nanoshell/polysaccharide nanofilm for controlled laser-assisted tissue thermal ablation, ACS Nano, 8 (2014) 5552-5563.

[15] C.H. Li, A.C. Jamison, S. Rittikulsittichai, T.C. Lee and T.R. Lee, In Situ Growth of Hollow Gold-Silver Nanoshells within Porous Silica Offers Tunable Plasmonic Extinctions and Enhanced Colloidal Stability, ACS Appl. Mater. Interfaces, 6 (2014) 19943-19950.

[16] J.F. Liao, W.T. Li, J.R. Peng, Q. Yang, H. Li, Y.Q. Wei, X.N. Zhang and Z.Y. Qian, Combined cancer photothermal-chemotherapy based on doxorubicin/gold nanorod-loaded polymersomes, Theranostics, 5 (2015) 345-356. 
[17] T.B. Huff, L. Tong, Y. Zhao, M.N. Hansen, J.X. Cheng and A. Wei, Hyperthermic effects of gold nanorods on tumor cells, Nanomedicine, 2 (2007) 125-132.

[18] J.Y. Chen, B. Wiley, Z.Y. Li, D. Campbell, F. Saeki, H. Cang, L. Au, J. Lee, X.D. Li and Y.N. Xia, Gold nanocages: Engineering their structure for biomedical applications, Adv. Mater., 17 (2005) 2255-2261.

[19] X.M. Yi, F.L. Wang, W.J. Qin, X.J. Yang and J.L. Yuan, Near-infrared fluorescent probes in cancer imaging and therapy: an emerging field, Int. J. Nanomed., 9 (2014) 1347-1365.

[20] J.V. Jokerst, T. Lobovkina, R.N. Zare and S.S. Gambhir, Nanoparticle PEGylation for imaging and therapy, Nanomedicine, 6 (2011) 715-728.

[21] K. Knop, R. Hoogenboom, D. Fischer and U.S. Schubert, Poly(ethylene glycol) in drug delivery: Pros and cons as well as potential alternatives, Angew. Chem.-Int. Edit., 49 (2010) 6288-6308.

[22] S.I. Jeon, J.H. Lee, J.D. Andrade and P.G. Degennes, Protein surface interactions in the presence of polyethylene oxide. 1. Simplified theory, J. Colloid Interface Sci., 142 (1991) 149158.

[23] S.I. Jeon and J.D. Andrade, Protein surface interactions in the presence of polyethylene oxide. 2. Effect of protein size, J. Colloid Interface Sci., 142 (1991) 159-166.

[24] P. Harder, M. Grunze, R. Dahint, G.M. Whitesides and P.E. Laibinis, Molecular conformation in oligo(ethylene glycol)-terminated self-assembled monolayers on gold and silver surfaces determines their ability to resist protein adsorption, J. Phys. Chem. B, 102 (1998) 426436.

[25] Q.G. Xu, L.M. Ensign, N.J. Boylan, A. Schön, X.Q. Gong, J.C. Yang, N.W. Lamb, S.T. Cai, T. Yu, E. Freirem and J. Hanes, Impact of surface polyethylene glycol (PEG) density on biodegradable nanoparticle transport in mucus ex vivo and distribution in vivo, ACS Nano, 10.1021/acsnano.5b03876 (2015).

[26] A. M., Properties of aqueous salt solutions of poly(ethylene oxide). Cloud points, $\theta$ temperatures, Colloid and Polymer Science, 265 (1987) 19-25.

[27] Z.G. Estephan, P.S. Schlenoff and J.B. Schlenoff, Zwitteration as an alternative to PEGylation, Langmuir, 27 (2011) 6794-6800.

[28] R.S. Porter and A. Casale, Recent studies of polymer reactions caused by stress, Polymer Engineering \& Science, 25 (1985) 129-156.

[29] S. Morlat and J.L. Gardette, Phototransformation of water-soluble polymers. I: photo- and thermooxidation of poly(ethylene oxide) in solid state, Polymer, 42 (2001) 6071-6079.

[30] Q. Shao and S.Y. Jiang, Molecular understanding and design of zwitterionic materials, Adv. Mater., 27 (2015) 15-26.

[31] S.Y. Jiang and Z.Q. Cao, Ultralow-fouling, functionalizable, and hydrolyzable zwitterionic materials and Their derivatives for biological applications, Adv. Mater., 22 (2010) 920-932.

[32] R.E. Holmlin, X.X. Chen, R.G. Chapman, S. Takayama and G.M. Whitesides, Zwitterionic SAMs that resist nonspecific adsorption of protein from aqueous buffer, Langmuir, 17 (2001) 2841-2850.

[33] M.C. Sin, P.T. Lou, C.H. Cho, A. Chinnathambi, S.A. Alharbi and Y. Chang, An intuitive thermal-induced surface zwitterionization for versatile, well-controlled haemocompatible organic and inorganic materials, Colloid Surf. B-Biointerfaces, 127 (2015) 54-64.

[34] S.F. Chen and S.Y. Jiang, A new avenue to nonfouling materials, Adv. Mater., 20 (2008) 335-338. 
[35] M.T. Cai, M.T. Leng, A.J. Lu, L. He, X.X. Xie, L. Huang, Y.H. Ma, J. Cao, Y.W. Chen and X.L. Luo, Synthesis of amphiphilic copolymers containing zwitterionic sulfobetaine as $\mathrm{pH}$ and redox responsive drug carriers, Colloid Surf. B-Biointerfaces, 126 (2015) 1-9.

[36] C.J. Huang and L.C. Wang, Bio-inspired multifunctional catecholic assembly for photoprogrammable biointerface, Colloid Surf. B-Biointerfaces, 134 (2015) 247-253.

[37] C.J. Huang, S.H. Chu, L.C. Wang, C.H. Li and T.R. Lee, Bio-inspired zwitterionic surface assembly with robust photostability and fouling resistance, ACS Appl. Mater. Interfaces, 7 (2015) 23776-23786.

[38] H. Wang, S. Chen, L. Li and S. Jiang, Improved Method for the Preparation of Carboxylic Acid and Amine Terminated Self-Assembled Monolayers of Alkanethiolates, Langmuir, 21 (2005) 2633-2636.

[39] P.C. Lee and D. Meisel, Adsorption and surface-enhanced raman of dyes on silver and gold sols, Journal of physical Chemistry, 86 (1982) 3391-3395.

[40] V. Vongsayat, B.M. Vittur, W.W. Bryan, J.H. Kim and T.R. Lee, Ultrasmall Hollow GoldSilver Nanoshells with Extinctions Strongly Red-Shifted to the Near-Infrared, ACS Appl. Mater. Interfaces, 3 (2011) 3616-3624.

[41] S.J. Oldenburg, R.D. Averitt, S.L. Westcott and N.J. Halas, Nanoengineering of optical resonances, Chemical Physics Letters, 288 (1998) 243-247.

[42] H. Tumturk, F. Sahin and E. Turan, Magnetic nanoparticles coated with different shells for biorecognition: high specific binding capacity, Analyst, 139 (2014) 1093-1100.

[43] L.X. Tiefenauer, G. Kuhne and R.Y. Andres, Antibody magnetite nanoparticles-In-vitro characterization of a potential tumor-specific contrast agent for magnetic resonance imaging, Bioconjugate Chem., 4 (1993) 347-352.

[44] N. Dinauer, S. Balthasar, C. Weber, J. Kreuter, K. Langer and H. von Briesen, Selective targeting of antibody-conjugated nanoparticles to leukemic cells and primary T-lymphocytes, Biomaterials, 26 (2005) 5898-5906.

[45] K. Uvdal, P. Bodo and B. Liedberg, L-cysteine adsorbed on gold and copper-An X-ray photoelectron-spectroscopy study, J. Colloid Interface Sci., 149 (1992) 162-173.

[46] H. Wang, S.F. Chen, L.Y. Li and S.Y. Jiang, Improved method for the preparation of carboxylic acid and amine terminated self-assembled monolayers of alkanethiolates, Langmuir, 21 (2005) 2633-2636.

[47] Z. Zhang, T. Chao, S.F. Chen and S.Y. Jiang, Superlow fouling sulfobetaine and carboxybetaine polymers on glass slides, Langmuir, 22 (2006) 10072-10077.

[48] C.L. He, Y.L. Liu, Z.P. Xue, M.T. Zheng, H.B. Wang, Y. Xiao, H.W. Dong, H.R. Zhang and B.F. Lei, Simple synthesis of carboxylate-rich porous carbon microspheres for highperformance supercapacitor electrode materials, Int. J. Electrochem. Sci., 8 (2013) 7088-7098.

[49] S. Sharma, R.W. Johnson and T.A. Desai, XPS and AFM analysis of antifouling PEG interfaces for microfabricated silicon biosensors, Biosens. Bioelectron., 20 (2004) 227-239.

[50] K.C. Popat, S. Sharma and T.A. Desai, Quantitative XPS analysis of PEG-modified silicon surfaces, J. Phys. Chem. B, 108 (2004) 5185-5188.

[51] M. Cerruti, S. Fissolo, C. Carraro, C. Ricciardi, A. Majumdar and R. Maboudian, Poly(ethylene glycol) monolayer formation and stability on gold and silicon nitride substrates, Langmuir, 24 (2008) 10646-10653.

[52] Z.Q. Cao and S.Y. Jiang, Super-hydrophilic zwitterionic poly(carboxybetaine) and amphiphilic non-ionic poly(ethylene glycol) for stealth nanoparticles, Nano Today, 7 (2012) 404-413. 
[53] Z.Q. Cao, L. Zhang and S.Y. Jiang, Superhydrophilic zwitterionic polymers stabilize liposomes, Langmuir, 28 (2012) 11625-11632.

[54] C.J. Huang, L. Mi and S.Y. Jiang, Interactions of alginate-producing and -deficient Pseudomonas aeruginosa with zwitterionic polymers, Biomaterials, 33 (2012) 3626-3631.

[55] E. Cukierman, R. Pankov and K.M. Yamada, Cell interactions with three-dimensional matrices, Current Opinion in Cell Biology, 14 (2002) 633-639.

[56] C.R. Simpson, M. Kohl, M. Essenpreis and M. Cope, Near-infrared optical properties of ex vivo human skin and subcutaneous tissues measured using the Monte Carlo inversion technique, Phys. Med. Biol., 43 (1998) 2465-2478.

[57] X.Y. Zhang, Gold nanoparticles: recent advances in the biomedical applications, Cell Biochem. Biophys., 72 (2015) 771-775.

[58] Y.P. Gao, Y.S. Li, J.Z. Chen, S.J. Zhu, X.H. Liu, L.P. Zhou, P. Shi, D.C. Niu, J.L. Gu and J.L. Shi, Multifunctional gold nanostar-based nanocomposite: Synthesis and application for noninvasive MR-SERS imaging-guided photothermal ablation, Biomaterials, 60 (2015) 31-41.

[59] X.H. Huang, I.H. El-Sayed, W. Qian and M.A. El-Sayed, Cancer cell imaging and photothermal therapy in the near-infrared region by using gold nanorods, J. Am. Chem. Soc., 128 (2006) 2115-2120.

[60] J.J. Shi, L. Wang, J. Zhang, R. Ma, J. Gao, Y. Liu, C.F. Zhang and Z.Z. Zhang, A tumortargeting near-infrared laser-triggered drug delivery system based on GO@Ag nanoparticles for chemo-photothermal therapy and X-ray imaging, Biomaterials, 35 (2014) 5847-5861.

[61] M. Das, N. Sanson, D. Fava and E. Kumacheva, Microgels loaded with gold nanorods: Photothermally triggered volume transitions under physiological conditions, Langmuir, 23 (2007) 196-201.

[62] C.J. Huang, J. Dostalek and W. Knoll, Optimization of layer structure supporting long range surface plasmons for surface plasmon-enhanced fluorescence spectroscopy biosensors, J. Vac. Sci. Technol. B, 28 (2010) 66-72.

[63] C.J. Huang, J. Dostalek, A. Sessitsch and W. Knoll, Long-range surface plasmon-enhanced fluorescence spectroscopy biosensor for ultrasensitive detection of E. coli O157:H7, Anal. Chem., 83 (2011) 674-677.

[64] C. Hoffmann and G.E.M. Tovar, Mixed self-assembled monolayers (SAMs) consisting of methoxy-tri(ethylene glycol)-terminated and alkyl-terminated dimethylchlorosilanes control the non-specific adsorption of proteins at oxidic surfaces, J. Colloid Interface Sci., 295 (2006) 427435.

[65] E. Nileback, L. Feuz, H. Uddenberg, R. Valiokas and S. Svedhem, Characterization and application of a surface modification designed for QCM-D studies of biotinylated biomolecules, Biosens. Bioelectron., 28 (2011) 407-413.

[66] P.K. Ajikumar, J. Kiat, Y.C. Tang, J.Y. Lee, G. Stephanopoulos and H.P. Too, Carboxylterminated dendrimer-coated bioactive interface for protein microarray: High-sensitivity detection of antigen in complex biological samples, Langmuir, 23 (2007) 5670-5677.

[67] Z.Z. Wang, T. Wilkop, J.H. Han, Y. Dong, M.J. Linman and Q. Cheng, Development of air-stable, supported membrane arrays with photolithography for study of phosphoinositide Protein interactions using surface plasmon resonance imaging, Anal. Chem., 80 (2008) 63976404.

[68] R. Vivek, R. Thangam, S.R. Kumar, C. Rejeeth, S. Sivasubramanian, S. Vincent, D. Gopi and S. Kannan, HER2 targeted breast cancer therapy with switchable "off/on" multifunctional 
"smart" magnetic polymer core-shell nanocomposites, ACS Appl. Mater. Interfaces, 8 (2016) 2262-2279.

[69] R. Huang, Y. Sun, Q.H. Gao, Q.C. Wang and B.W. Sun, Trastuzumab-mediated selective delivery for platinum drug to HER2-positive breast cancer cells, Anti-Cancer Drugs, 26 (2015) 957-963.

[70] H.W. Chen, L.Y. Wang, Q.Q. Yu, W.P. Qian, D. Tiwari, H. Yi, A.Y. Wang, J. Huang, L.L. Yang and $\mathrm{H}$. Mao, Anti-HER2 antibody and ScFvEGFR-conjugated antifouling magnetic iron oxide nanoparticles for targeting and magnetic resonance imaging of breast cancer, Int. J. Nanomed., 8 (2013) 3781-3794.

[71] K. Kerman, D. Ozkan, P. Kara, B. Meric, J.J. Gooding and M. Ozsoz, Voltammetric determination of DNA hybridization using methylene blue and self-assembled alkanethiol monolayer on gold electrodes, Anal. Chim. Acta, 462 (2002) 39-47.

[72] M.J.B. Wissink, R. Beernink, J.S. Pieper, A.A. Poot, G.H.M. Engbers, T. Beugeling, W.G. van Aken and J. Feijen, Immobilization of heparin to EDC/NHS-crosslinked collagen. Characterization and in vitro evaluation, Biomaterials, 22 (2001) 151-163.

[73] C.J. Huang, N.D. Brault, Y.T. Li, Q.M. Yu and S.Y. Jiang, Controlled hierarchical architecture in surface-initiated zwitterionic polymer brushes with structurally regulated functionalities, Adv. Mater., 24 (2012) 1834-1837.

[74] C.J. Huang, Y.T. Li and S.Y. Jiang, Zwitterionic polymer-based platform with two-layer architecture for ultra low fouling and high protein loading, Anal. Chem., 84 (2012) 3440-3445. 


\section{FIGURE CAPTIONS}

Figure 1. XPS spectra of $\mathrm{C} 1 \mathrm{~s}, \mathrm{~N} 1 \mathrm{~s}$, and $\mathrm{S} 2 \mathrm{p}$ regions for SAMs derived from (a) Cys-b and (b) OEG-thiol. The SAMs were prepared on planar evaporated Au substrates.

Figure 2. The static contact angles on bare Au and Au modified with Cys-b and OEG-thiol. The measurements were performed at least three times for each sample.

Figure 3. Bacterial adsorption on samples of bare Au and Au modified with Cys-b and OEGthiol. Gram-negative $P$. aeruginosa and gram-positive S. epidermidis were dissolved in PBS and incubated with substrates for $3 \mathrm{~h}$ at $37{ }^{\circ} \mathrm{C}$. After washing with PBS, adsorbed bacteria were stained with Live/Dead dye and imaged with a fluorescence microscope (a). The quantitative results of bacteria numbers were estimated using ImageJ software (b). Scale bars in all images represent $10 \mu \mathrm{m}$.

Figure 4. The adhesion of $3 \mathrm{~T} 3$ fibroblasts on bare Au and Au modified with Cys-b and OEGthiol. The cells were cultured on samples in culture medium containing 1\% FBS for $72 \mathrm{~h}$ at $37^{\circ} \mathrm{C}$. (a) After washing with PBS, images of the cells taken with optical microscopy. (b) Quantitative results of cell numbers and relative cell areas estimated using ImageJ software. The scale bars in all images represent $100 \mu \mathrm{m}$.

Figure 5. (a) The extinction spectra of as-prepared, Cys-b-, and OEG-modified nanoshells. (b) DLS measurements of particle size as a function of incubation time in BSA solution.

Figure 6. Time evolution of the extinction spectra of nanoshells modified with (a) Cys-b and (b) OEG-thiol, where the samples were dissolved in $3 \mathrm{M} \mathrm{NaCl}$ solution, and the temperature was 
maintained at $50{ }^{\circ} \mathrm{C}$. (c) Relative intensity of the extinction at $808 \mathrm{~nm}$ over $24 \mathrm{~h}$. (d) Photolytic heating of nanoshell solutions by laser irradiation at $808 \mathrm{~nm}$.

Figure 7. Nanoshell-assisted NIR plasmonic hyperthermia for HER2-negative NIH 3 T3 and HER2-positive MDA-MB-453 cells. (a) Fluorescence images of NIH 3 T3 fibroblasts treated with as-synthesized nanoshells and nanoshells modified with Cys-b and OEG-thiol and those conjugated with anti-HER2 antibodies, after irradiation of NIR light. (b) Fluorescence images of MDA-MB-453 cells with the same treatments as NIH 3T3. Viable cells were stained green with calcein, and dead cells were stained red with EthD-1. Scale bars represent $100 \mu \mathrm{m}$. (c) Quantitative cell death percentages for NIH 3T3 and MDA-MB-453 cells with different modified nanoshells. 
Figure 1.
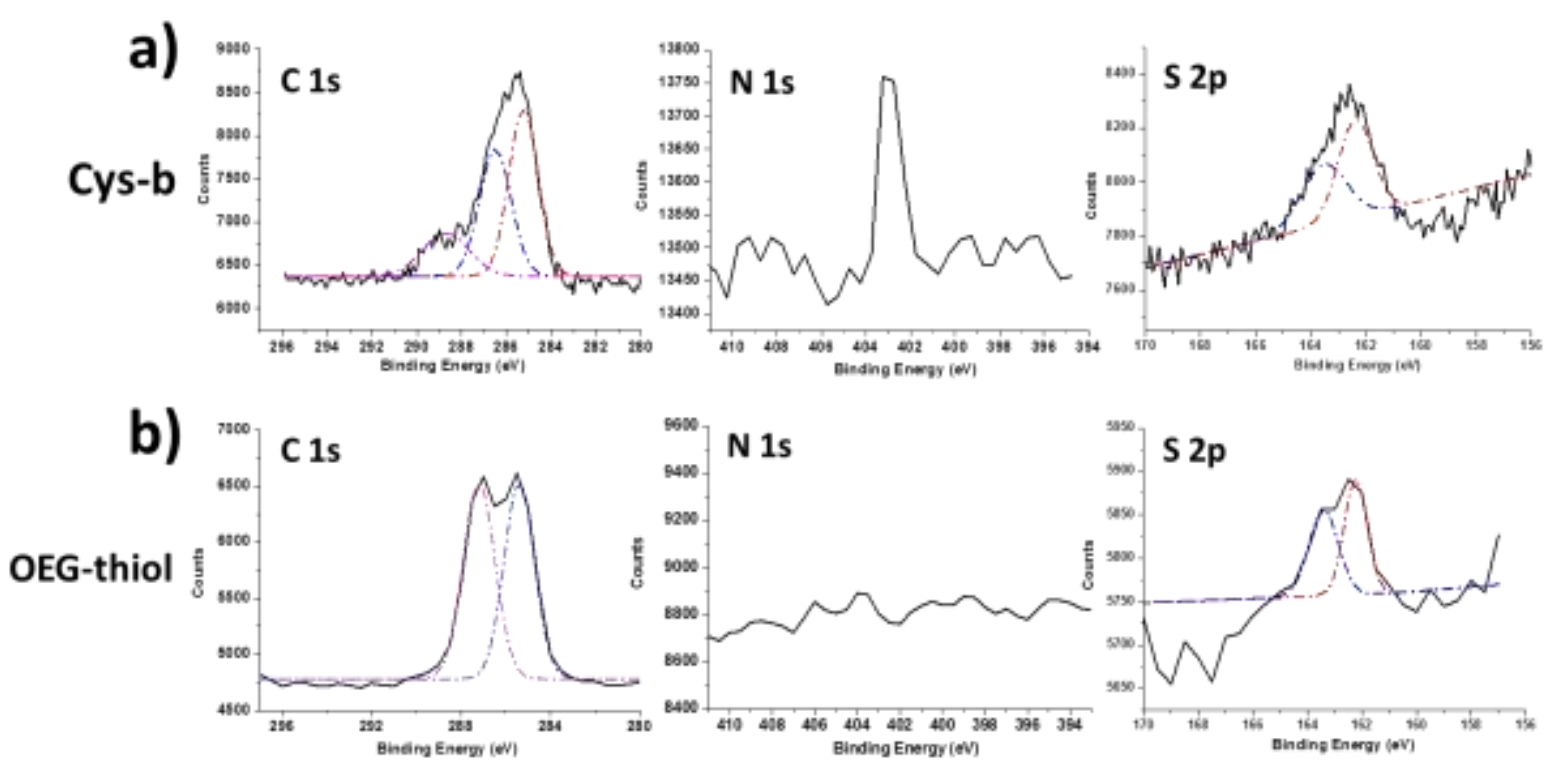
Figure 2.

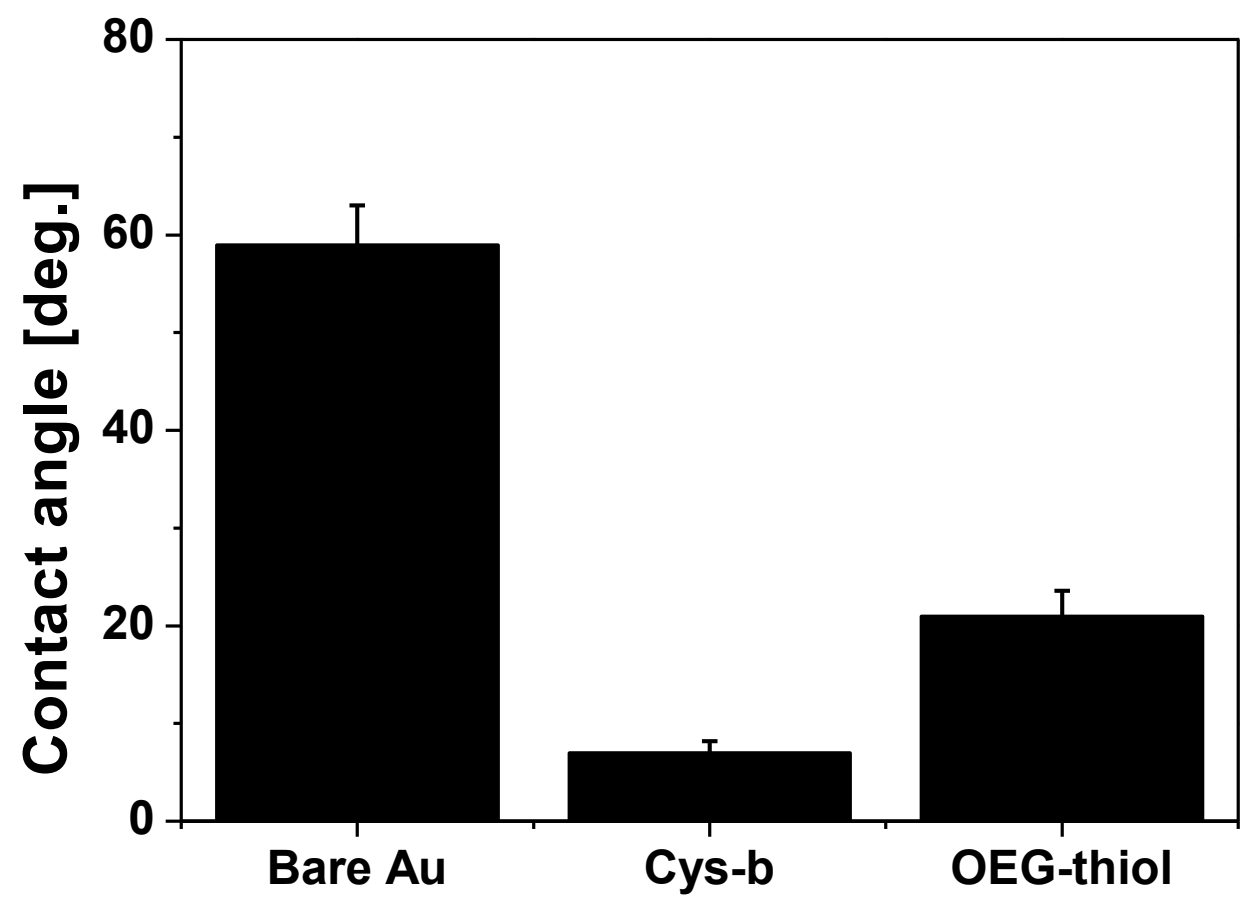


Figure 3.

a) Pseudomonas aeruginosa (G-)

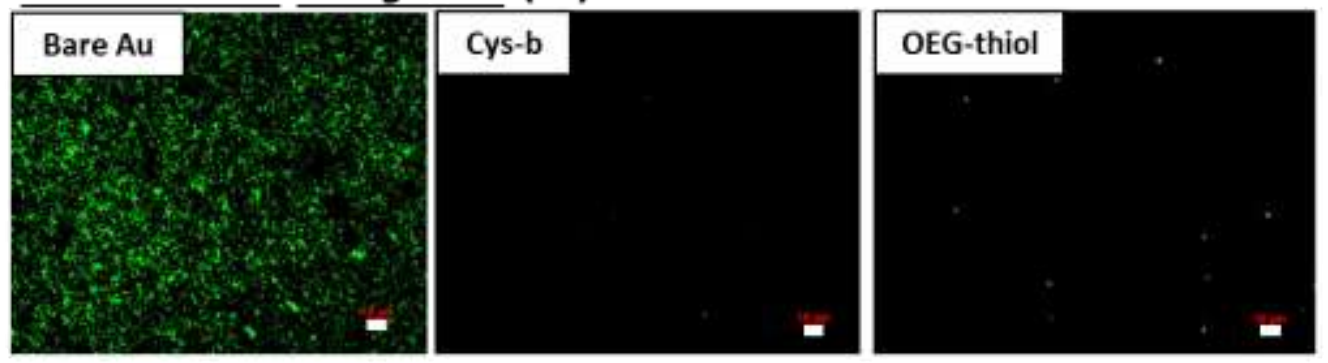

Staphylococcus epidermidis (G+)
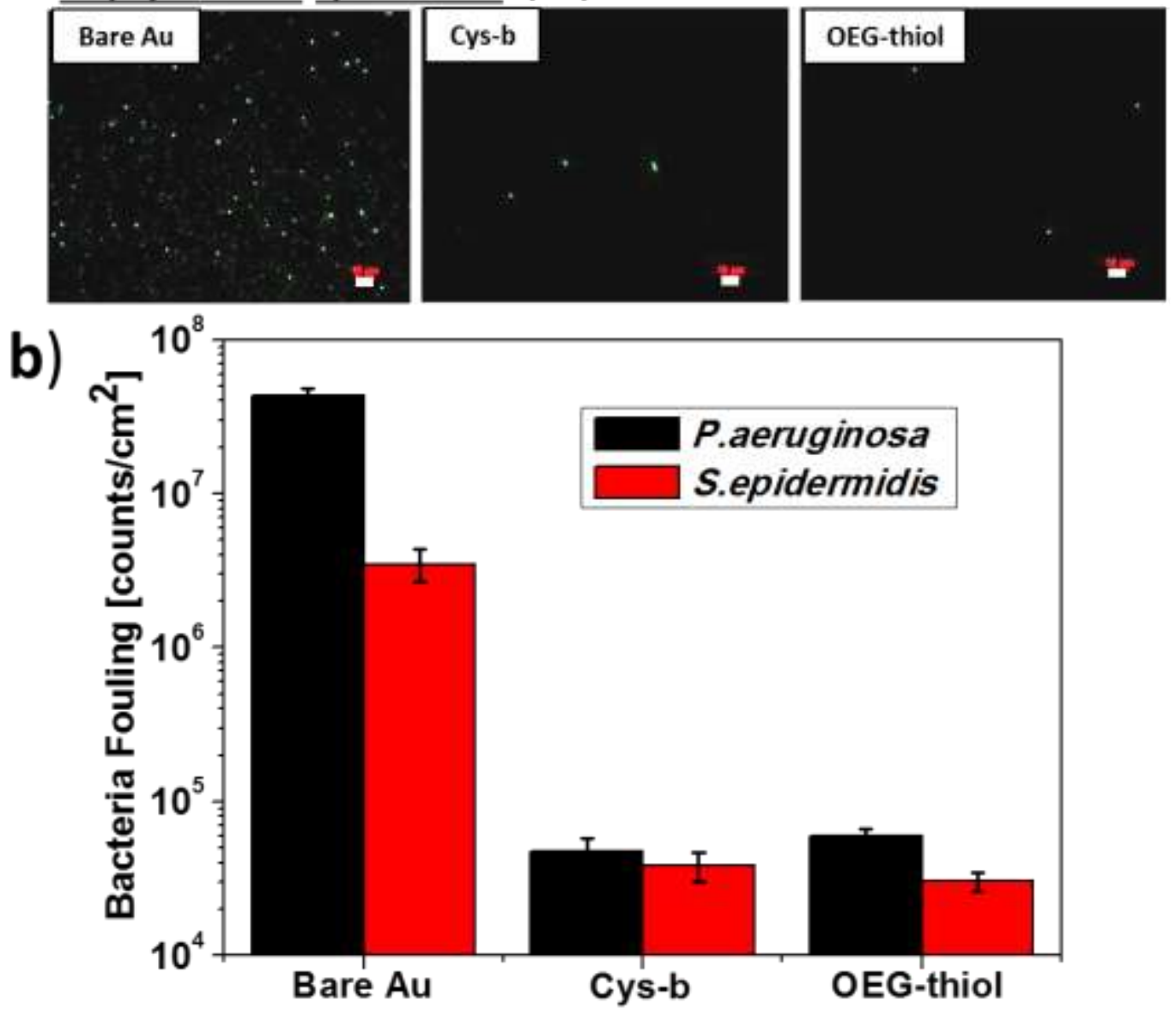
Figure 4.

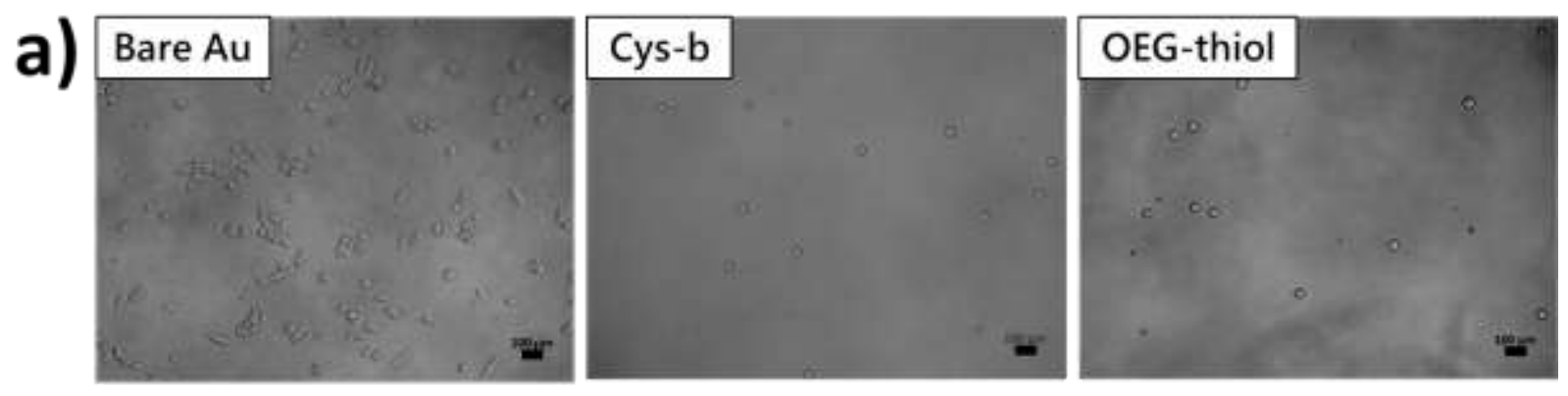

b)

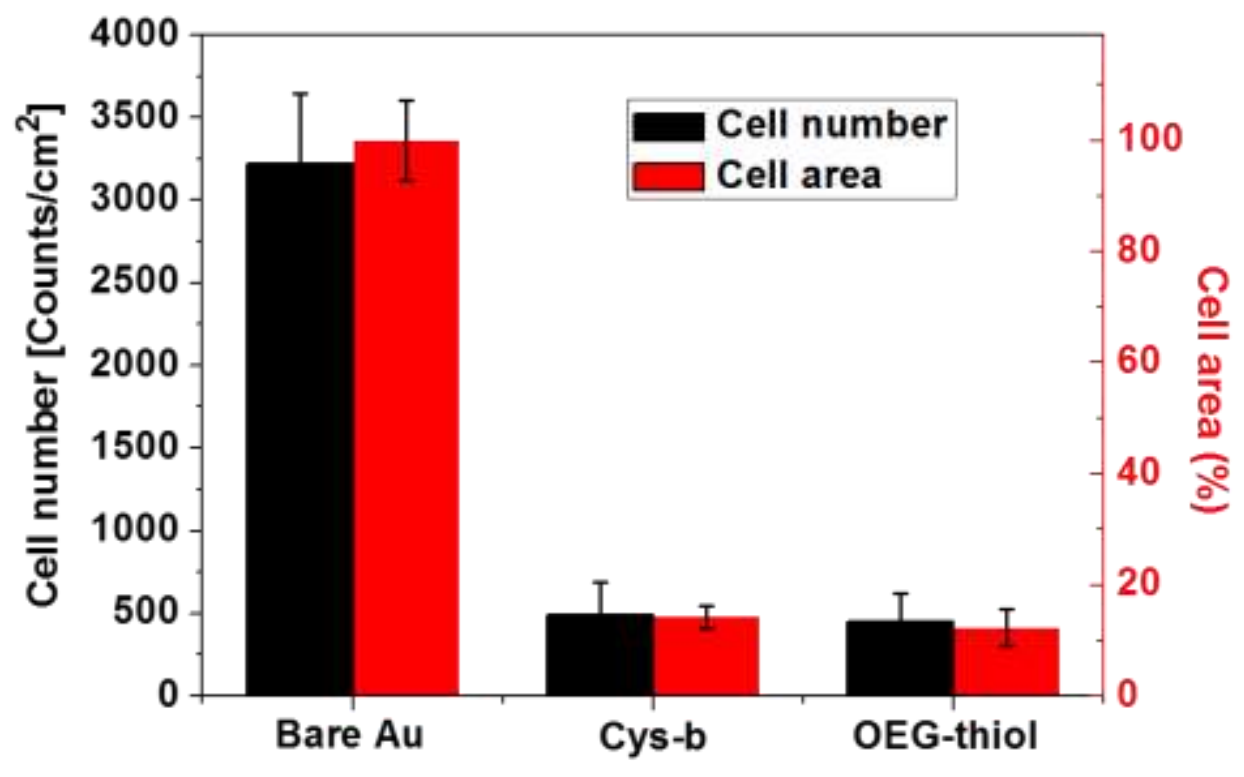


Figure 5.
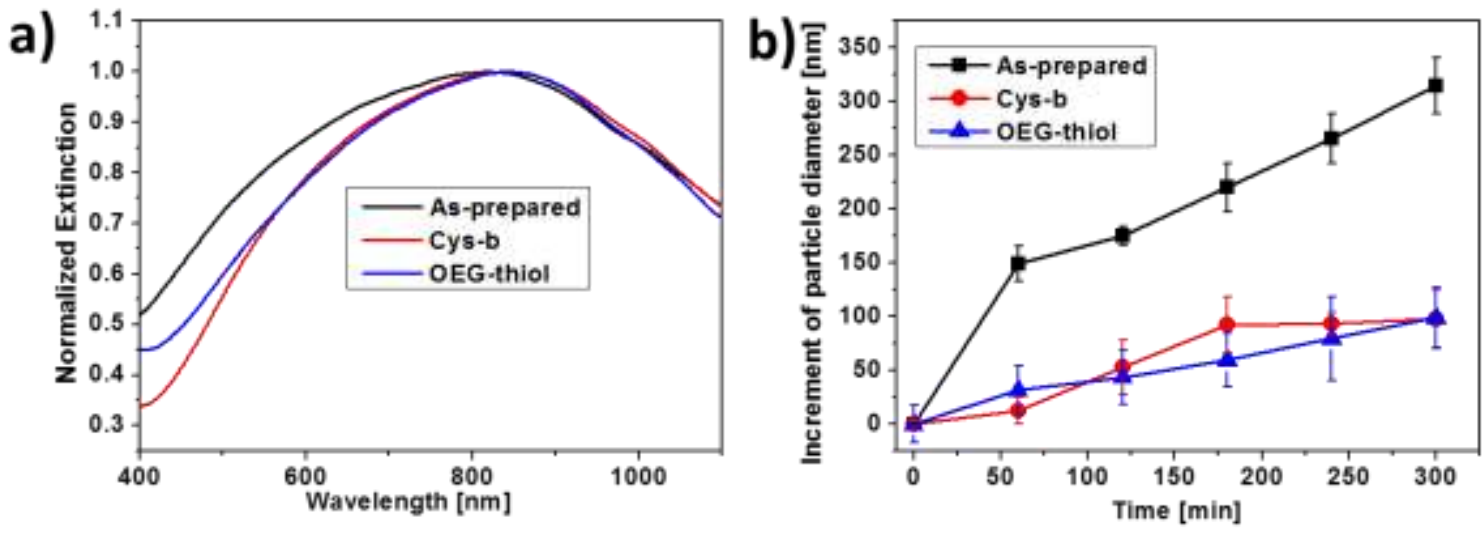
Figure 6.

a)

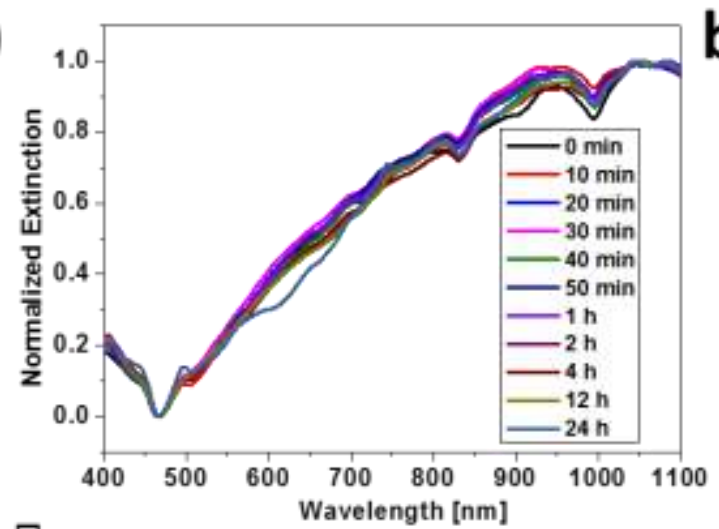

c)

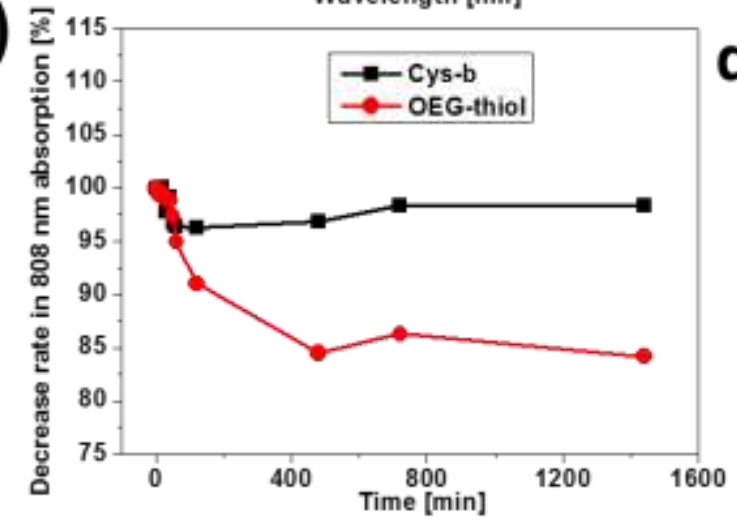

b)

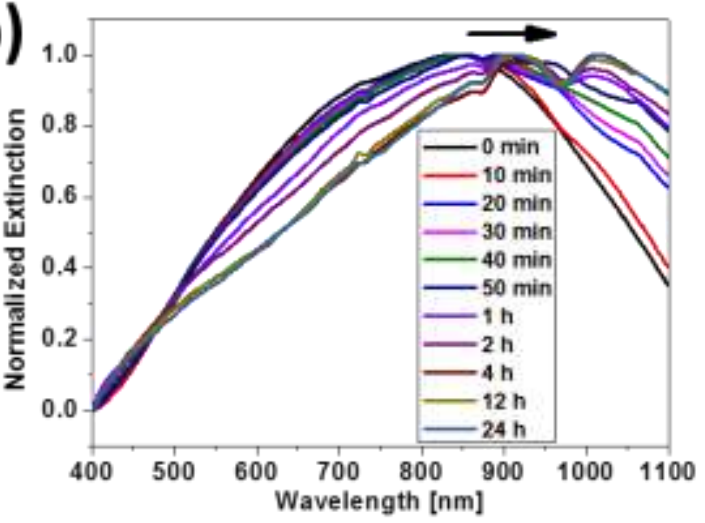

d)

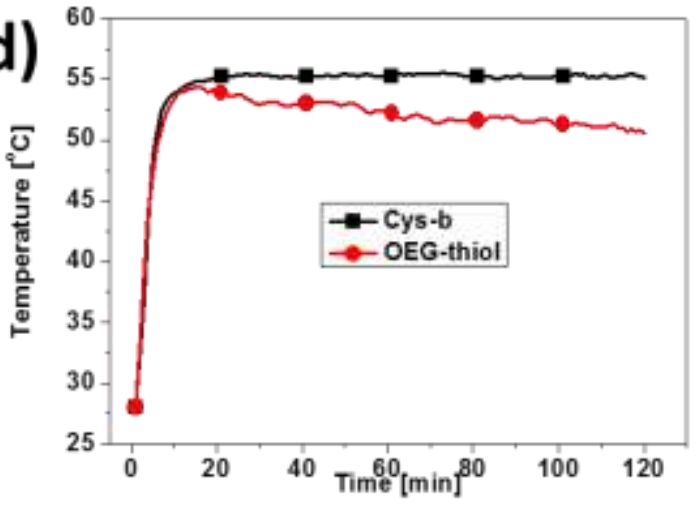


Figure 7.

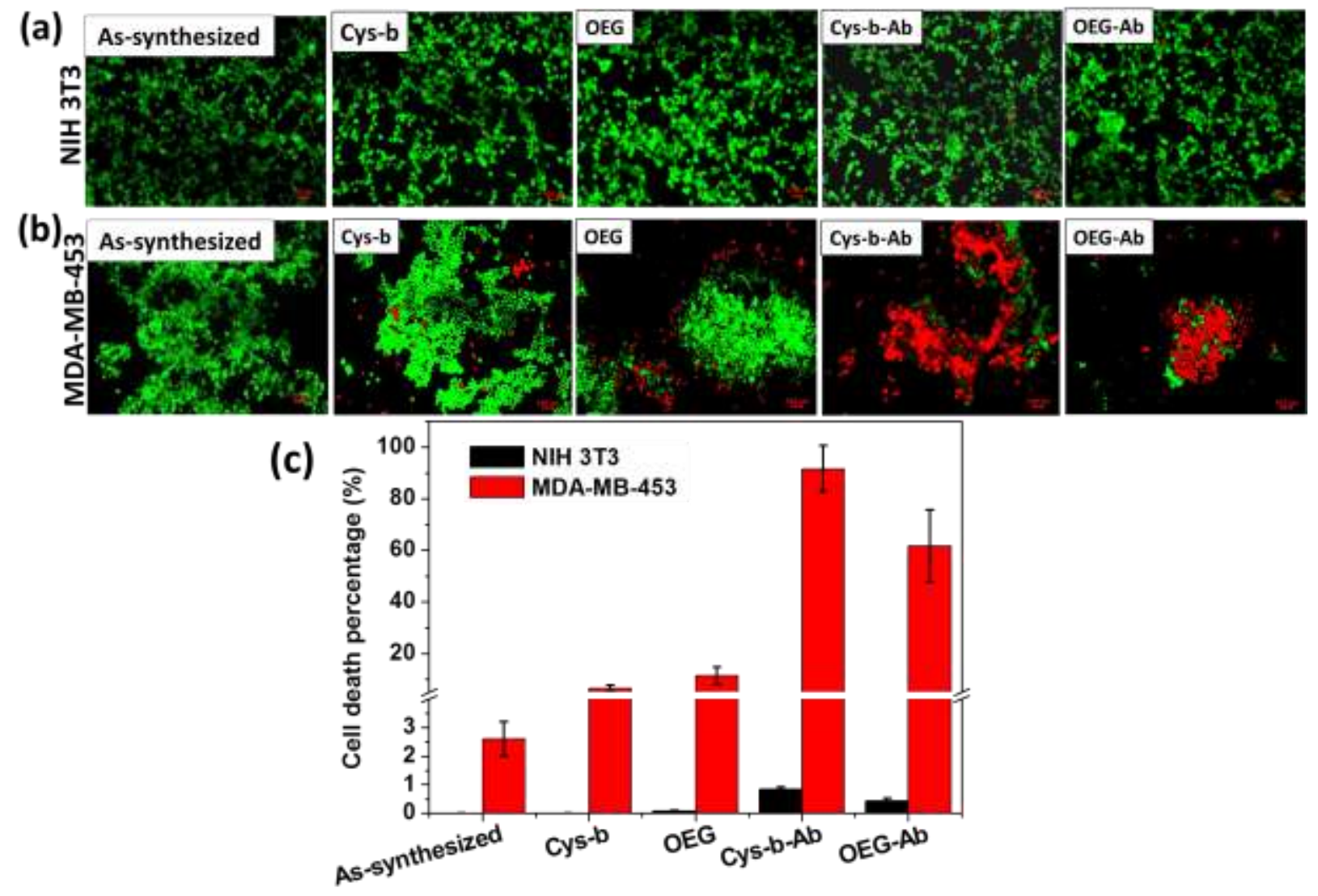


Graphical Abstract

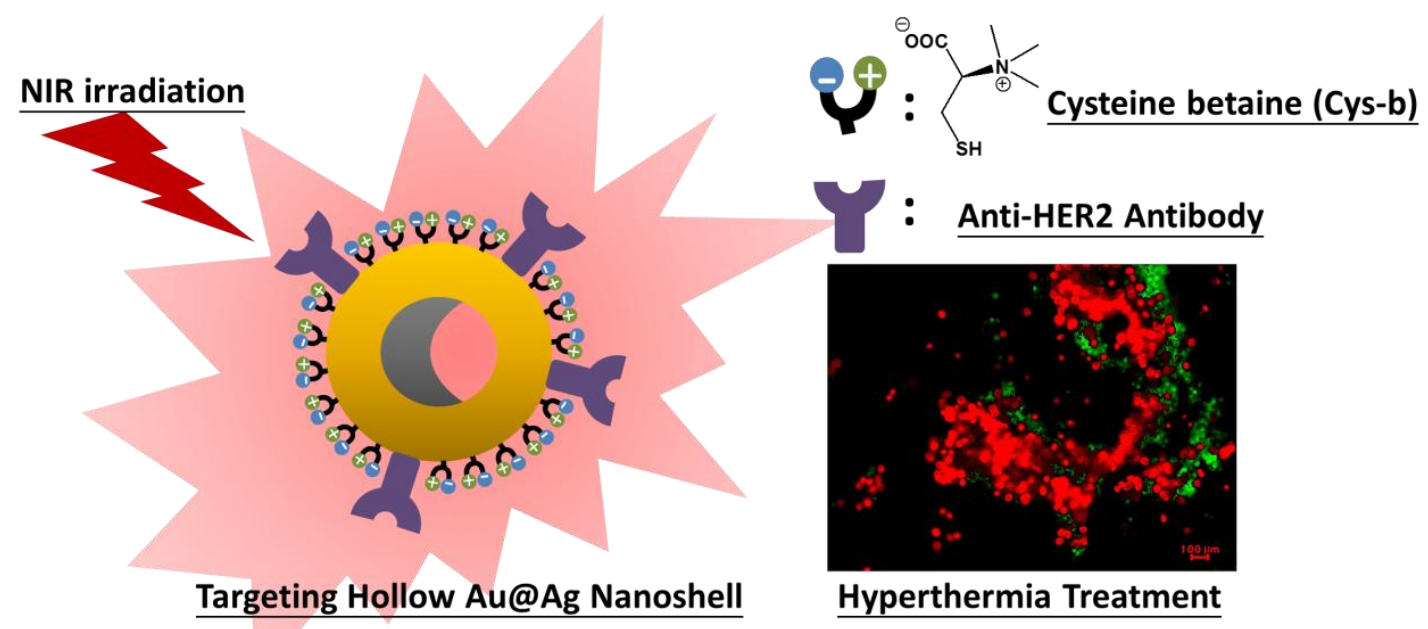

